\title{
Psychosocial morbidity and its correlates in cancer patients of the Mediterranean area: findings from the Southern European Psycho-Oncology Study
}

\author{
Luigi Grassi $^{\mathrm{a}, *}$, Luzia Travado ${ }^{\mathrm{b}}$, Francisco Luis Gil Moncayo ${ }^{\mathrm{c}}$, Silvana Sabato ${ }^{\mathrm{a}}$, \\ Elena Rossi ${ }^{\mathrm{a}}$ and the SEPOS Group ${ }^{1}$ \\ ${ }^{\mathrm{a}}$ Department of Behaviour and Communication, Section of Psychiatry, University of Ferrara and Department of Mental Health and \\ General University S. Anna Hospital, Corso Giovecca 203, 44100 Ferrara, Italy \\ ${ }^{\mathrm{b}}$ Psychotherapy Service, Hospital S. José and Faculty of Psychology, Independent University, Lisbon, Portugal \\ ${ }^{c}$ Psycho-Oncology Unit, Hospital Duran i Reynals, Catalan Institute of Oncology, L'Hospitalet, Barcelona, Spain
}

Received 5 March 2004; received in revised form 20 July 2004; accepted 20 July 2004

\begin{abstract}
Background: A few and partial data are available on psychosocial morbidity among cancer patients in Mediterranean countries. As a part of a more general investigation (Southern European Psycho-Oncology Study-SEPOS), the rate of psychosocial morbidity and its correlation with clinical and cultural variables were examined in cancer patients in Italy, Portugal and Spain. Methods: A convenience sample of cancer outpatients with good performance status and no cognitive impairment were approached. The Hospital Anxiety-Depression scale (HAD-S), the Mini-Mental Adjustment to Cancer scale (Mini-MAC), and the Cancer Worries Inventory (CWI) were used to measure psychological morbidity, coping strategies and concerns about illness.

Results: Of 277 patients, $34 \%$ had pathological scores ("borderline cases" plus "true cases") on HAD-S Anxiety and $24.9 \%$ on HAD-S Depression. Total psychiatric "caseness" was $28.5 \%$ and $16.6 \%$, according to different HAD cut-offs (14 and 19 , respectively). Significant relationships of HAD-S Anxiety, HAD-S Depression, HAD-S Total score, with Mini-MAC Hopeless and Anxious Preoccupation, and CWI score were found. No differences emerged between countries on psychosocial morbidity, while some differences emerged between the countries on coping mechanisms. Furthermore, Fatalism, Avoidance and marginally Hopeless were higher compared to studies carried out in English-speaking countries.
\end{abstract}

* Corresponding author. Clinica Psichiatrica, Università di Ferrara Corso Giovecca 203, 44100 Ferrara, Italy. Tel.: +39 0532 236809; fax: +390532 212240 .

E-mail address: luigi.grassi@unife.it (L. Grassi).

${ }^{1}$ In the SEPOS project ("Improving health staff's communication and assessment skills of psychosocial morbidity and quality of life in cancer patients: a study in Southern European countries", Principal Investigator Luigi Grassi, M.D.), the following persons participated in different ways: Michele Tomamichel, MD (CH), Paolo Zanotti, PhD $(\mathrm{CH})$, Purification Lluch, PhD (E); Ricardo Campos, MD (E); Maria Francisca Hollenstein (E), Jorge Maté (E); Katia Magnani, PhD (I); Silvana Sabato, PhD (I); Elena Rossi, PhD (I); Giulia Tralli, PhD (I); Cidalia Ventura, $\mathrm{PhD}(\mathrm{P})$; Cristina Martins, $\mathrm{PhD}(\mathrm{P})$; Sonia Cunha, $\mathrm{PhD}(\mathrm{P})$; Rute Pires, $\mathrm{PhD}(\mathrm{P})$. 
Limitations: The relatively small sample size and the good performance status prevent us to generalize data on patients with different cancer sites and advanced phase of illness.

Conclusions: One-third of the patients presented anxiety and depressive morbidity, with significant differences in characteristics of coping in Mediterranean countries in comparison with English-speaking countries.

(c) 2004 Elsevier B.V. All rights reserved.

Keywords: Psychosocial morbidity; Cancer; SEPOS

\section{Introduction}

Several studies have shown that $40 \%$ to $50 \%$ of cancer patients report psychiatric disorders, especially depression (Sellick and Crooks, 1999). Increased length of stay in the hospital (Prieto et al., 2002), maladaptive coping (Watson et al., 1991), poor quality of life (Grassi et al., 1996), poor response to chemotherapy (Walker et al., 1999), risk of suicide (Henrikkson et al., 1995), and risk of recurrence of cancer (Watson et al., 1999) have been related to psychosocial morbidity.

While cultural issues have been indicated as important variables to be considered when evaluating psychosocial aspects of cancer (Chambers, 2000; Holland, 2004), a few data are available in the Mediterranean area, where problems in doctor-patient communication and paternalistic attitudes represent major obstacles in eliciting psychosocial problems secondary to cancer (Arraras et al., 1995; Mystadikou et al., 1996; Grassi et al., 2000).

In order to extend the knowledge on this topic, the Southern European Psycho-Oncology Study (SEPOS) was set up. The aims were: (i) to examine the rate of psychosocial morbidity and related variables in cancer patients; (ii) to rate the ability of oncologists to detect their patients' psychosocial morbidity; and (iii) to develop and apply a training model to improve doctors' skills in recognizing psychological disorders. In the present study, findings relative to the first aim are reported.

\section{Methods}

The study was conducted in three countries of the European Union, namely Italy (Hospital S. Anna, Ferrara), Spain (Hospital Duran i Reynals, Barcelona) and Portugal (Hospital S. José, Lisbon), and in a non-
EU country (Switzerland, Lugano Hospital) ${ }^{2}$. A convenience sample of cancer outpatients meeting the following criteria was recruited: an age between 18 and 70 years; a diagnosis of cancer between 6 and 18 months; a Karnofosky Performance Status scale $\geq 80$ (Karnofsky and Burchenal, 1949); and no cognitive deficits due to disease or treatment. The study was approved by the ethical committee or related boards of the hospitals and each patient gave his/her written consent to participate.

The Hospital Anxiety-Depression scale (HAD-S) (Zigmond and Snaith, 1983) was used to assess anxiety and depression. According to Carroll et al., 1993, scores between 8 and 10 on Anxiety and Depression subscales indicate "borderline" cases, while scores $\geq 11$ identify "clinical" "cases". The cut-off scores of 14 and 19 on the HAD-S Total were used to evaluate "likely psychiatric caseness" (Ibbotson et al., 1994) and "caseness" (Razavi et al., 1990), respectively.

The Mini-Mental Adjustment to Cancer scale (Mini-MAC) (Watson et al., 1994) was used to assess coping to cancer, namely Hopeless, Fighting Spirit, Anxious Preoccupation, Fatalism, and Avoidance. Provisional cut-off scores on Anxious Preoccupation and Hopeless (mean score \pm 1 SD) were used to assess maladaptive coping (Watson et al., 1989).

A modified version of the Cancer Worries Inventory (CWI) (D'Errico et al., 1999) was used to rate the main preoccupations caused by cancer (e.g. physical and emotional problems, relational worries).

Student's $t$-test, ANOVA, Pearson's $r$ correlation test, and chi-square test were used when appropriate.

\footnotetext{
${ }^{2}$ Data from Switzerland are still in progress and are not reported here.
} 


\section{Results}

Of 287 patients participating, data were available for 277 (Italy, $n=119$; Portugal, $n=90$, Spain, $n=68$ ). The patients' socio-demographic and clinical characteristics are reported in Table 1 . Portuguese patients were the oldest $(60.06 \pm 11.16$ years $)$ and Spanish the youngest (53.82 \pm 15.55 years) $(F=4.9, d f, 2$, $p=0.008$ ). There was a higher prevalence of males in the Spanish (57.4\%) than in the Portuguese group $(10 \%) \quad\left(\chi^{2}=44.96, d f, 2, p=0.001\right)$. Education was higher among Spanish (mean $11.88 \pm 6.37$ years) and lower among Portuguese patients $(5.09 \pm 3.18$ years $)$

Table 1

Socio-demographic and clinical data of the patients

\begin{tabular}{ll}
\hline Sex & \\
Male & $77(27.8 \%)$ \\
Female & $200(72.2 \%)$ \\
Age (years) & $57.46 \pm 12.59$ \\
Education & \\
No education & $8(2.8 \%)$ \\
$\leq 8$ years & $154(55.6 \%)$ \\
13 years & $60(21.66 \%)$ \\
$>18$ years & $44(15.88 \%)$ \\
no information & $11(3.97 \%)$ \\
Marital status & \\
Never-married & $26(9.4 \%)$ \\
Separated/divorced & $21(7.6 \%)$ \\
Married & $205(74 \%)$ \\
Widowed & $24(8.7 \%)$ \\
Unknown & $1(0.4 \%)$ \\
Occupation & \\
Employed & $83(30 \%)$ \\
Unemployed & $7(2.5 \%)$ \\
Housewives & $39(14.1 \%)$ \\
Retired & $126(45.5 \%)$ \\
Students & $2(0.7 \%)$ \\
Other & $17(6.1 \%)$ \\
Unknown & $3(1.1 \%)$ \\
Cancer site & \\
Gastrointestinal & $62(22.4 \%)$ \\
Blood & $30(10.8 \%)$ \\
Genito-urinary & $18(6.5 \%)$ \\
Breast & $141(50.9 \%)$ \\
Respiratory & $12(4.3 \%)$ \\
Skin & $2(0.7 \%)$ \\
Other & $12(4.3 \%)$ \\
Ltage & \\
Local disease & $133(48 \%)$ \\
Metastatic & $95(34.3 \%)$ \\
\hline & $49(17.7 \%)$ \\
\hline
\end{tabular}

( $F=39.5, d f .2, p=0.001$ ). Significant differences were also reported on stage of illness, with the highest prevalence of metastatic patients in Italy $(32.7 \%)$ and the lowest in Portugal $(3.8 \%) \quad\left(\chi^{2}=30.96, d f, 4\right.$, $p=0.001$ ).

\subsection{Psychosocial morbidity and maladaptive coping}

Forty-seven subjects (17\%) proved to be "clinical cases" on HAD-S Anxiety and 25 (9\%) on HAD-S Depression (cut-off score=11). A further group of patients were "borderline cases" (HAD-S score 8-10), specifically $47(17 \%)$ on HAD-S Anxiety and 44 (15.9\%) on HAD-S Depression, yielding a total of 94 patients (34\%) with anxiety and 69 (24.9\%) with depression. On the HAD-S Total, 79 subjects (28.5\%) were "likely psychiatric cases" (cut-off=14), and 46 (16.6\%) were "cases" (cut-off=19).

Maladaptive coping was found in 94/277 patients $(33.93 \%)$, with $58(20.94 \%)$ reporting high scores on Anxious Preoccupation and $36(13 \%)$ on Hopeless.

Significant correlations were found between HAD$\mathrm{S}$ and both CWI Total and Mini-MAC Hopeless and Anxious Preoccupation (see Table 2 for details).

\subsection{Correlation with other variables}

Females reported higher scores on the Mini-MAC Anxious Preoccupation (16.96 \pm 5.41 vs. 19.23 \pm 5.23 , $t=3.2, p=0.002)$ and Fatalism $(14.34 \pm 2.72$ vs. $15.56 \pm 3.1, t=3.03, p=0.003)$ than males. No difference was found on any psychological measure according to stage and treatment. Breast cancer patients $(n=141,50.9 \%)$ did not differ from the group of patients affected by other cancers $(n=136,49.1 \%)$ on HAD-S "caseness".

A similar prevalence was found between the three centres on borderline and clinical anxiety $\left(\chi^{2}=6.71\right.$, $d f, 4, \quad p=0.15)$, borderline and clinical depression $\left(\chi^{2}=7.08, d f, 4, p=0.13\right)$, and total "caseness" (HAD$\mathrm{S}>14, \chi^{2}=0.66, d f, 2, p=0.99 ;$ HAD-S $>19, \chi^{2}=0.88$, $d f, 2, \quad p=0.64)$. Italian patients reported marginally higher scores on HAD-S Depression $(F=3.63, d f, 2$, $p=0.028)$ and marginally lower scores on HAD-S Anxiety ( $F=3.73, d f, 2, p=0.025)$. Portuguese patients reported higher scores on the Mini-MAC Fighting Spirit $(F=4.55, d f, 2, p=0.01)$, Fatalism $(F=26.01$, 
Table 2

Correlation between the psychological measures

\begin{tabular}{|c|c|c|c|c|c|c|c|c|}
\hline & $\begin{array}{l}\text { HAD-S } \\
\text { Anxiety }\end{array}$ & $\begin{array}{l}\text { HAD-S } \\
\text { Depression }\end{array}$ & $\begin{array}{l}\text { HAD-S } \\
\text { total }\end{array}$ & $\begin{array}{l}\text { Fighting } \\
\text { Spirit (FS) }\end{array}$ & $\begin{array}{l}\text { Hopeless } \\
(\mathrm{H})\end{array}$ & $\begin{array}{l}\text { Fatalism } \\
\text { (F) }\end{array}$ & $\begin{array}{l}\text { Anxious } \\
\text { Preoccupation (AP) }\end{array}$ & $\begin{array}{l}\text { Avoidance } \\
(\mathrm{Av})\end{array}$ \\
\hline HAD-S Depression & $0.57 * *$ & & & & & & & \\
\hline HAD-S total & $0.89 * *$ & $0.88 * *$ & & & & & & \\
\hline FS & -0.06 & $-0.34 *$ & $-0.22 *$ & & & & & \\
\hline $\mathrm{H}$ & $0.51 * *$ & $0.54 * *$ & $0.59 * *$ & $-0.28^{*}$ & & & & \\
\hline $\mathrm{F}$ & -0.01 & -0.09 & -0.06 & $0.41 * *$ & -0.01 & & & \\
\hline $\mathrm{AP}$ & $0.61 * *$ & $0.45 * *$ & 0.60 & -0.01 & $0.54 * *$ & 0.15 & & \\
\hline Av & 0.11 & -0.07 & -0.02 & $0.28 *$ & 0.04 & $0.35^{*}$ & 0.21 & \\
\hline CWI & $0.61 * *$ & $0.50 * *$ & 0.63 & -0.12 & $0.53 * *$ & -0.01 & $0.57 * *$ & 0.05 \\
\hline
\end{tabular}

$* p=0.01$.

** $p=0.001$.

$d f, 2, p=0.001)$, and Avoidance $(F=6.24, d f, 2, p=0.01)$ (Table 3).

In comparison with the English normative data on the Mini-MAC (Watson, personal communication), higher scores on Fatalism $(15.25 \pm 3.05$ vs. $13.76 \pm 2.91$, $t=6.86, p=0.001)$, Avoidance (12.04 \pm 3.35 vs. $9.49 \pm 2.5, t=12.29, p=0.001$ ), and, marginally, Hopeless $(12.63 \pm 5.03$ vs. $11.96 \pm 3.91, t=2.11, p=0.036)$ were found in our study.

\section{Discussion}

This is the first investigation comparing psychosocial data among cancer patients in the Mediterranean area.

Approximately one third of the patients were "cases" or "likely cases", as far as anxiety and depression are concerned. These data are similar to what reported by Moorey et al. (1991) who found a $27 \%$ prevalence of HAD-S anxiety and a $20.1 \%$ prevalence of depression, while Carroll et al. (1993) pointed out a prevalence of $42 \%$ and $8.1 \%$, respectively. In line with Razavi et al.'s (1990) study, "caseness" (HAD-S Total) ranged between 16\% (probable major psychiatric disorder) and 28\% (general psychiatric "caseness"). Taken together, our data confirm that psychosocial morbidity is a significant clinical problem in Southern European cancer patients.

A second result was that hopelessness and anxious preoccupation were the most significant coping styles associated with psychosocial morbidity. This is in agreement with data showing that both pessimistic responses and extreme focusing on illness are indicators of maladjustment to cancer (Watson et al., 1991). In contrast with previous research (Greer et al., 1990), the role of fighting spirit was not significant in

Table 3

Mean (and standard deviation) for the single psychological measures in the total sample and according to country

\begin{tabular}{|c|c|c|c|c|c|c|}
\hline Measures & Total $(n=277)$ & Italy $(n=119)$ & Portugal $(n=90)$ & Spain $(n=68)$ & $F$ & $\mathrm{p}$ \\
\hline \multicolumn{7}{|l|}{ HAD-S } \\
\hline Anxiety & $6.48(4.27)$ & $5.57(3.86)$ & $7.21(4.35)$ & $6.86(4.59)$ & 3.63 & ns \\
\hline Depression & $4.62(4.11)$ & $5.41(4.50)$ & $4.10(3.66)$ & $4.07(3.95)$ & 3.73 & ns \\
\hline Total score & $11.1(7.41)$ & $10.99(7.66)$ & $11.35(7.26)$ & $10.94(7.46)$ & 0.1 & ns \\
\hline \multicolumn{7}{|l|}{ Mini-MAC } \\
\hline Fighting Spirit & $12.62(2.21)$ & $12.19(2.30)$ & $13.10(2.24)$ & $12.71(1.86)$ & 4.55 & 0.01 \\
\hline Hopeless & $12.63(5.03)$ & $13.24(5.76)$ & $12.04(4.06)$ & $12.35(4.79)$ & 1.60 & ns \\
\hline Fatalism & $15.25(3.05)$ & $14.59(3.01)$ & $16.95(2.68)$ & $14.05(2.59)$ & 26.01 & 0.001 \\
\hline Anxious Preoccupation & $18.65(5.81)$ & $18.93(6.48)$ & $19.18(5.54)$ & $17.38(4.65)$ & 2.16 & ns \\
\hline Avoidance & $12.04(3.35)$ & $11.39(3.72)$ & $13.00(2.87)$ & $11.89(2.97)$ & 6.24 & 0.002 \\
\hline Cancer Worries Inventory & $13.49(10.65)$ & $12.43(10.13)$ & $14.28(11.55)$ & $14.19(10.25)$ & 0.98 & ns \\
\hline
\end{tabular}


this study. However, more recently it has been shown that hopelessness, rather than fighting spirit, was a key factor in influencing cancer patients' quality of life and possibly survival (Watson et al., 1999). Furthermore, hopelessness and anxious preoccupation were found to be the only factors improving after antidepressant treatment among breast cancer patients (Grassi et al., 2004).

As expected, psychosocial morbidity was associated with the extent of concerns about illness. This confirms the relationship of worries with psychological maladjustment (Spencer et al., 1999; Mathews et al., 2002) and underscores the need for an early and routine assessment of the impact of cancer on the patients and their emotional response (Maguire et al., 1996).

Regarding the role of cultural factors, minor differences were found between the participating centres on psychosocial morbidity (i.e. anxiety, depression, and "caseness") and cancer-related worries. More data are necessary to interpret the differences in coping (Mini-MAC) between Portuguese patients, on the one hand, and Italian and Spanish, on the other. Education, gender and age can be possible explanatory factors, as well as more specific cultural variables which need to be studied in more detail. Likewise, further research is necessary to understand the differences (higher fatalism, avoidance and hopelessness) between Southern and Northern European patients.

Important limitations should be mentioned. First, psychosocial morbidity was not evaluated by using a structured clinical interview, which could have given more detailed data. Second, the small size of the sample and the good performance status prevent us from generalizing the results to patients in an advanced phase of illness and poorer performance status. Third, even if the sample was representative of the centres and the regions where the study was carried out, we cannot generalize the results to the whole cancer population of the three countries. Fourth, most patients were females with a diagnosis of early breast cancer and this does not allow us to understand the role of gender and medical variables on psychosocial morbidity in this specific cultural setting. Lastly, variables related to religious beliefs, namely the Catholic tradition in Mediterranean countries, were not taken into consideration and should be explored in future studies.
To conclude, at least one third of Southern European cancer patients presented clinical anxiety and depression, which were associated with maladaptive coping and worries about their disease. The cultural aspects of this geographical area should be the focus of further studies both in educational and clinical research.

\section{Acknowledgements}

The study has been funded by the European Commission DG Health and Consumer Protection (Agreement with the University of FerraraSI2.307317 2000CVGG2-026). The research group wishes to thank all the patients and colleagues participating in the study. The authors are indebted to Paul Packer for his support in revising the manuscript.

\section{References}

Arraras, J.I., Illarramendi, J.J, Valerdi, J.J., James, S., 1995. Truth-telling to the patient in advanced cancer: family information filtering and prospect for change. Psychooncology 4, $191-196$.

Carroll, B.T., Kathol, R.G., Noyes Jr. Wald , T.G., Clamon, G.H, 1993. Screening for depression and anxiety in cancer patients using the Hospital Anxiety and Depression Scale. Gen. Hosp. Psychiatry $15,69-74$.

Chambers, T., 2000. Cross-cultural issues in caring for patients with cancer. Cancer Treat. Res. 102, 23-37.

D’Errico, G.M., Galassi, J.P., Schanberg, R., Ware, W.B., 1999. Development and validation of the Cancer Worries Inventory: a measure of illness-related cognitions. J. Psychosoc. Oncol. 17, $119-137$.

Grassi, L., Indelli, M., Marzola, M., Maestri, A., Santini, A., Piva, E., Boccalon, M., 1996. Depression and quality of life in home care assisted cancer patients. J. Pain Symptom Manage. 12, 300-307.

Grassi, L., Giraldi, T., Messina, E.G., Magnani, K., Valle, E., Cartei, G., 2000. Physicians' attitudes and problems in truth-telling to cancer patients. Supp. Care Cancer 8, 40-45.

Grassi, L., Biancosino, B., Marmai, L., Righi, R., 2004. Effect of reboxetine on major depressive disorders in breast cancer patients: an open-label study. J. Clin. Psychiatry 49, 215-221.

Greer, S., Morris, T., Pettingale, K.W., Haybittle, J.L., 1990. Psychological response to breast cancer and 15-year outcome. Lancet 335 (8680), 49-50.

Henrikkson, M.M., Isometsä, E.T., Hietanen, P.S., Aro, H.M., Lönqvist, J.K., 1995. Mental disorders in cancer suicides. J. Affect Disord. 36, 11-20. 
Holland, J.C., 2004. IPOS Sutherland Memorial Lecture: an international perspective on the development of psychosocial oncology: overcoming cultural and attitudinal barriers to improve psychosocial care. Psychooncology 13, 445-459.

Ibbotson, T., Maguire, P., Selby, P., Priestman, T., Wallace, L., 1994. Screening for anxiety and depression in cancer patients: the effects of disease and treatment. Eur. J. Cancer 30A, 37-40.

Karnofsky, D.A., Burchenal, J.H., 1949. The clinical evaluation of chemotherapeutic agents in cancer. In: MacLeod, C.M (Ed.), Evaluation of Chemotherapeutic Agents. Columbia University Press, NY, pp. 191-205.

Maguire, P., Faulkner, A., Booth, K., Elliott, C., Hillier, V., 1996. Helping cancer patients disclose their concerns. Eur. J. Cancer 32A, 78-81.

Mathews, A., Ridgeway, V., Warren, R., Britton, P., 2002. Predicting worry following a diagnosis of breast cancer. Psychooncology 1, 415-418.

Moorey, S., Greer, S., Watson, M., Gorman, C., Rowden, L., Tunmore, R., Robertson, B., Bliss, J., 1991. The factor structure and factor stability of the hospital anxiety and depression scale in patients with cancer. Br. J. Psychiatry 158, 255-259.

Mystadikou, K., Liossi, C., Vlachos, L., Papadimitroiu, J., 1996. Disclosure of diagnostic information to cancer patients in Greece. Palliat. Med. 10, 195-200.

Prieto, J.M., Blanch, J., Atala, J., Carreras, E., Rovira, M., Cirera, E., Gasto, C., 2002. Psychiatric morbidity and impact on hospital length of stay among hematologic cancer patients receiving stemcell transplantation. J. Clin. Oncol. 20, 1907-1917.

Razavi, D., Delvaux, N., Farvacques, C., Robaye, E., 1990. Screening for adjustment disorders and major depressive disorders in cancer in-patients. Br. J. Psychiatry 156, 79-83.
Sellick, S.M., Crooks, D.L., 1999. Depression and cancer: an appraisal of the literature for prevalence, detection, and practice guideline development for psychosocial interventions. Psychooncology 8, 315-333.

Spencer, S.M., Lehman, J.M., Wynings, C., Arena, P., Carver, C.S., Antoni, M.H., Derhagopian, R.P., Ironson, G., Love, N., 1999. Concerns about breast cancer and relations to psychosocial wellbeing in a multiethnic sample of early-stage patients. Health Psychol. 18, 159-168.

Walker, L.G., Heys, S.D., Walker, M.B., Ogston, K., Miller, I.D., Hutcheon, A.W., Sarkar, T.K., Ah-See, A.K., Eremin, O., 1999. Psychological factors can predict the response to primary chemotherapy in patients with locally advanced breast cancer. Eur. J. Cancer 35, 1783-1788.

Watson, M., Greer, S., Bliss, J.M., 1989. Mental Adjustment to Cancer (MAC) Scale Users' Manual. CRC Psychological Medicine Unit, Sutton, U.K.

Watson, M., Greer, S., Rowden, L., Gorman, C., Robertson, B., Bliss, J.M., Tunmore, R., 1991. Relationships between emotional control, adjustment to cancer and depression and anxiety in breast cancer patients. Psychol. Med. 21, 51-57.

Watson, M., Haviland, J.S., Greer, S., Davidson, J., Bliss, J.M., 1999. Influence of psychological response on survival in breast cancer: a population-based cohort study. Lancet 354, $1331-1336$.

Watson, M., Law, M., dos Santos, M., Greer, S., Baruch, J., Bliss, J., 1994. The mini-MAC: further development of the mental adjustment to cancer scale. J. Psychosoc. Oncol. 12, $33-46$.

Zigmond, A.S., Snaith, R.P., 1983. The hospital anxiety and depression scale. Acta Psychiatr. Scand. 67, 361-370. 